Supporting information

\title{
Stability profile of transition metal oxides in the oxygen evolution reaction in alkaline medium
}

Aliki Moysiadou and Xile $\mathrm{Hu}^{*}$

Laboratory of Inorganic Synthesis and Catalysis, Institute of Chemical Sciences and Engineering, École Polytechnique Fédérale de Lausanne (EPFL), ISIC-LSCI, 1015 Lausanne, Switzerland

*E-mail: xile.hu@epfl.ch 


\section{Calibration of electrodes}

\section{$\mathrm{Hg} / \mathrm{HgO}$ reference electrode}

For all electrochemical experiments performed in strong alkaline media, an $\mathrm{Hg} / \mathrm{HgO} / 1 \mathrm{M} \mathrm{KOH}$ reference electrode (RE) was used due to its stability at high $\mathrm{pH}$ values. The filling solution was the same as the alkaline electrolyte in the cell in order to mitigate cross contamination and avoid a potential ohmic drop. Prior to use, the RE was calibrated with respect to the reversible hydrogen electrode (RHE). For this purpose, Pt was used as both counter (CE) and working (WE) electrodes. Hydrogen gas was bubbled directly on the WE and the potential was cycled between about +100 and $-100 \mathrm{mV}$ vs. RHE in $1 \mathrm{M} \mathrm{KOH}$. Figure S1 shows a typical polarization curve. More negative to the equilibrium potential of HER, the current increases exponentially due to the hydrogen evolution, while more positive to the RHE the current is due to hydrogen oxidation. The crossing point is the RHE potential. The reference electrode was calibrated periodically to ensure its stability.

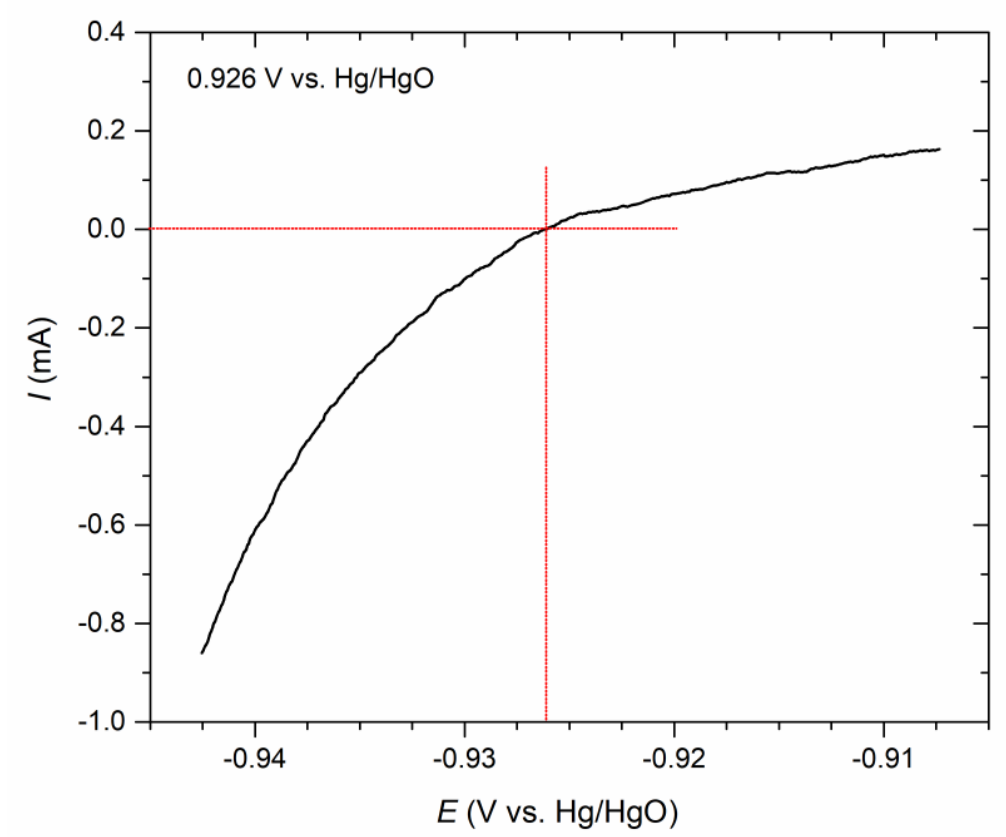

Figure S1. Calibration of the $\mathrm{Hg} / \mathrm{HgO}$ electrode with respect to the reversible hydrogen electrode.

\section{Au-coated quartz crystals}

It is important to calibrate every new crystal prior to its use in order to calculate the sensitivity factor, $\mathrm{C}_{\mathrm{f}}$, which under typical experimental conditions can slightly vary. The calibration of the $10 \mathrm{MHz} A u-c o a t e d$ quartz crystals was based on the two-electron reduction of $\mathrm{Cu}^{2+}$ from a $\mathrm{CuSO}_{4}$ solution and its subsequent oxidation onto the Au electrode. A solution of $10 \mathrm{mM} \mathrm{CuSO}_{4}$ in $1 \mathrm{M} \mathrm{H}_{2} \mathrm{SO}_{4}$ was prepared and placed in the Teflon cell. The potential was cycled 5 times between -0.250 and $0.300 \mathrm{~V}$ vs. $\mathrm{Ag} / \mathrm{AgCl}$ at a scan rate of 0.05 $\mathrm{V} / \mathrm{s}$ while the frequency response of the QCM was recorded. The sensitivity factor was calculated by 
combining the charge passed during the reduction of cupric ions to metallic copper according to equations (1) and (2).

$\mathrm{CuSO}_{4}(\mathrm{aq})+2 \mathrm{e}^{-} \rightleftharpoons \mathrm{Cu}(\mathrm{s})+\mathrm{SO}_{4}^{2-}(\mathrm{aq})$

The experimental value of the sensitive factor was $228 \mathrm{~Hz} \mathrm{ug}^{-1} \mathrm{~cm}^{2}$, close to the theoretical value: $226 \mathrm{~Hz} \mu \mathrm{g}^{-1}$ $\mathrm{cm}^{2} .1$

Sauerbrey equation ${ }^{2,3}: \quad \Delta f=-\frac{2 f_{o}^{2}}{A\left(\mu_{q} \rho_{q}\right)^{\frac{1}{2}}} \Delta m=-C_{f} \Delta m(2)$,

Where $\Delta f$ is the measured frequency shift,

$f_{0}$ the frequency of the quartz crystal,

A the piezoelectrically active area,

$\mu_{\mathrm{q}}$ the shear modulus,

$\rho_{\mathrm{q}}$ the density of the quartz crystal,

$\mathrm{C}_{f}$ the sensitivity factor,

$\Delta m$ the mass change. 


\section{X-ray Photoelectron Spectroscopy}
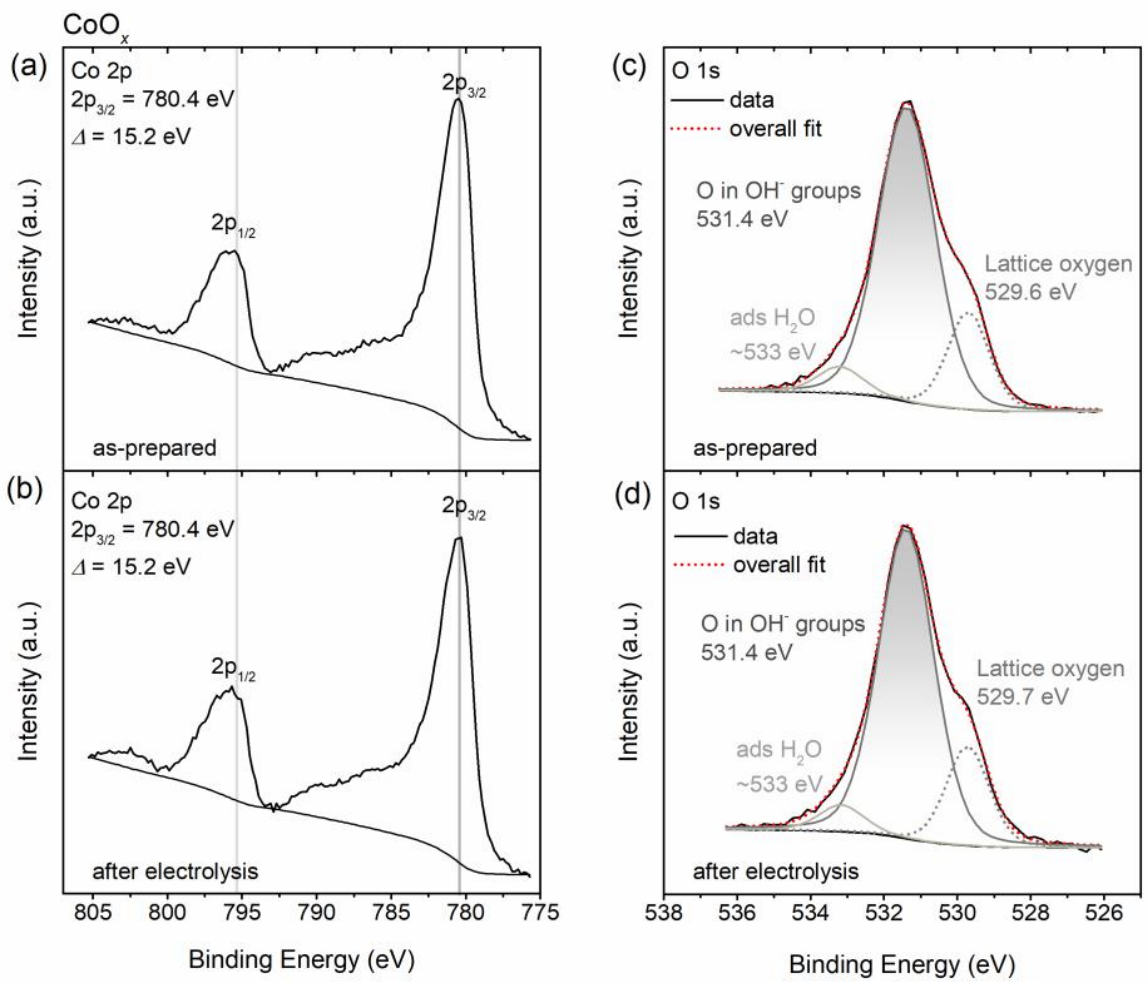

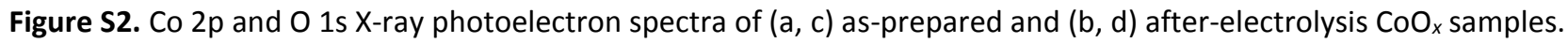
The as-prepared samples were subjected to galvanostatic electrolysis at a current density of $5 \mathrm{~mA} / \mathrm{cm}^{2}$ in $1 \mathrm{M} \mathrm{KOH}$ for 6 hours. 

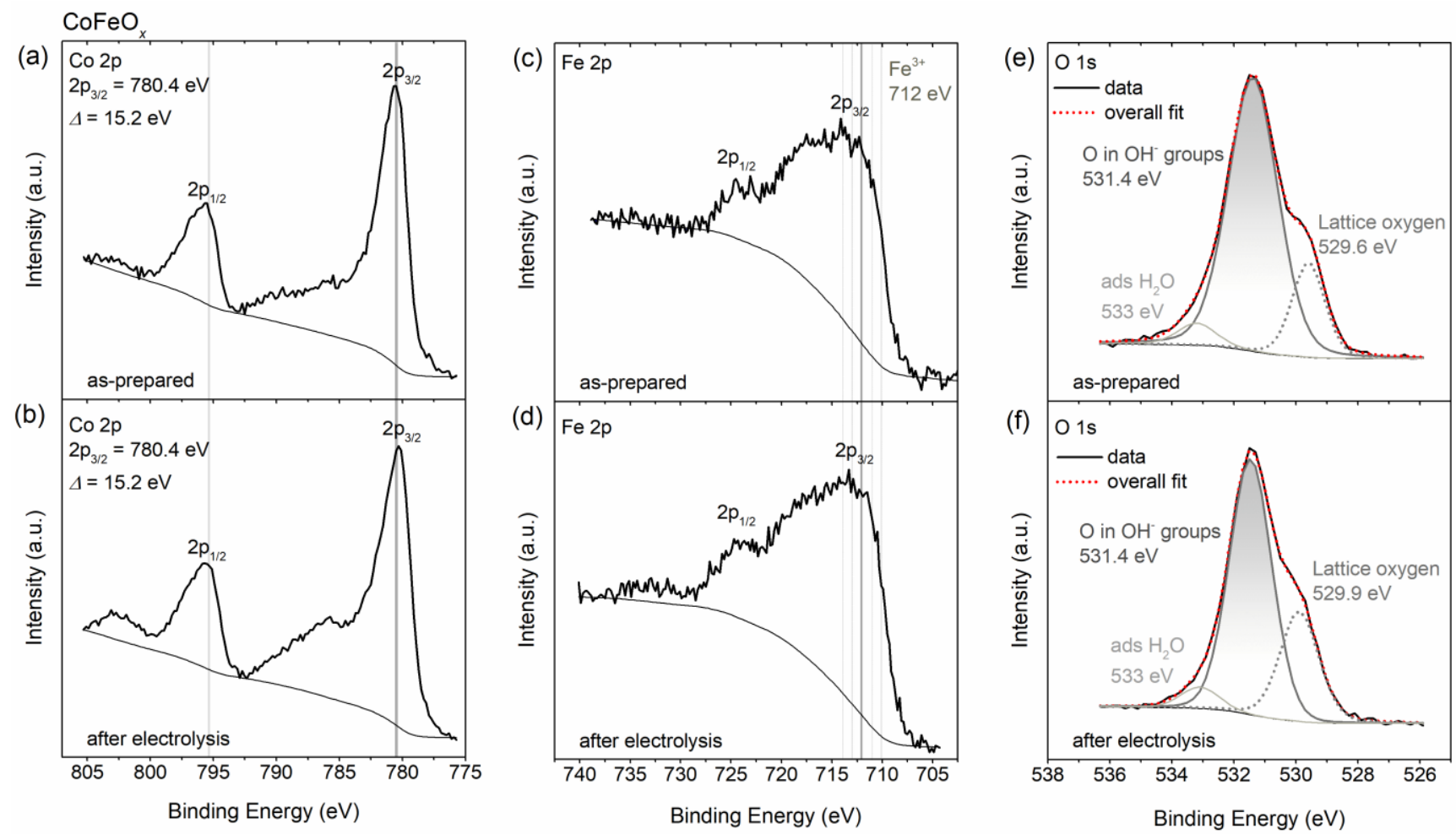

Figure S3. Co 2p, Fe 2p and O 1s X-ray photoelectron spectra of (a, c, e) as-prepared and (b, d, f) after-electrolysis $\mathrm{CoFeO}_{x}$ samples. The as-prepared samples were subjected to galvanostatic electrolysis at a current density of $5 \mathrm{~mA} / \mathrm{cm}^{2}$ in $1 \mathrm{M} \mathrm{KOH}$ for 6 hours. 

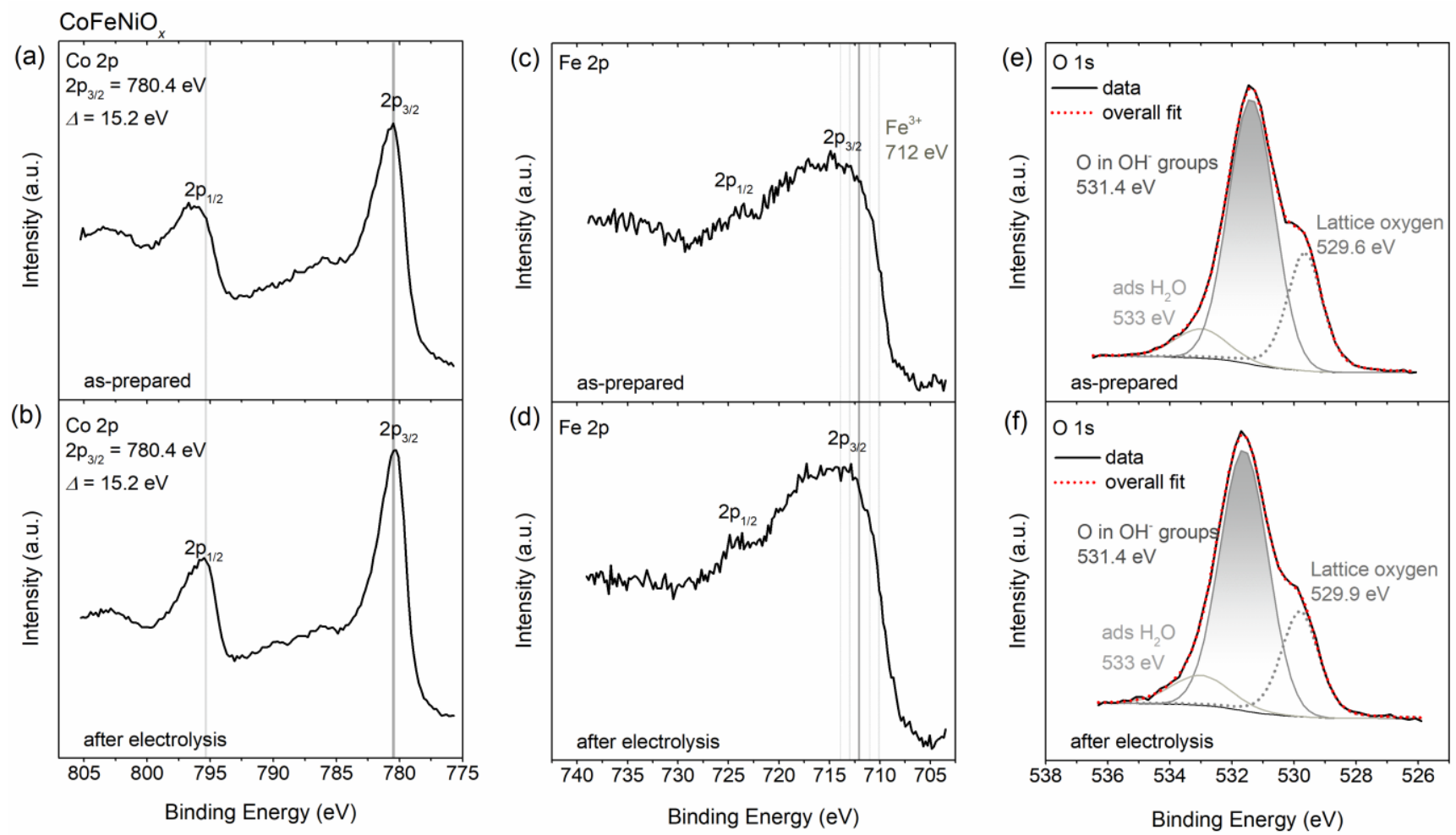

Figure S4. Co 2p, Fe 2p and O 1s X-ray photoelectron spectra of (a, c, e) as-prepared and (b, d, f) after-electrolysis $\mathrm{CoFeNiO}_{x}$ samples. The $\mathrm{Ni}$ signal was very weak due to the very low concentration of nickel in the film. The as-prepared samples were subjected to galvanostatic electrolysis at a current density of $5 \mathrm{~mA} / \mathrm{cm}^{2}$ in $1 \mathrm{M} \mathrm{KOH}$ for 6 hours. 

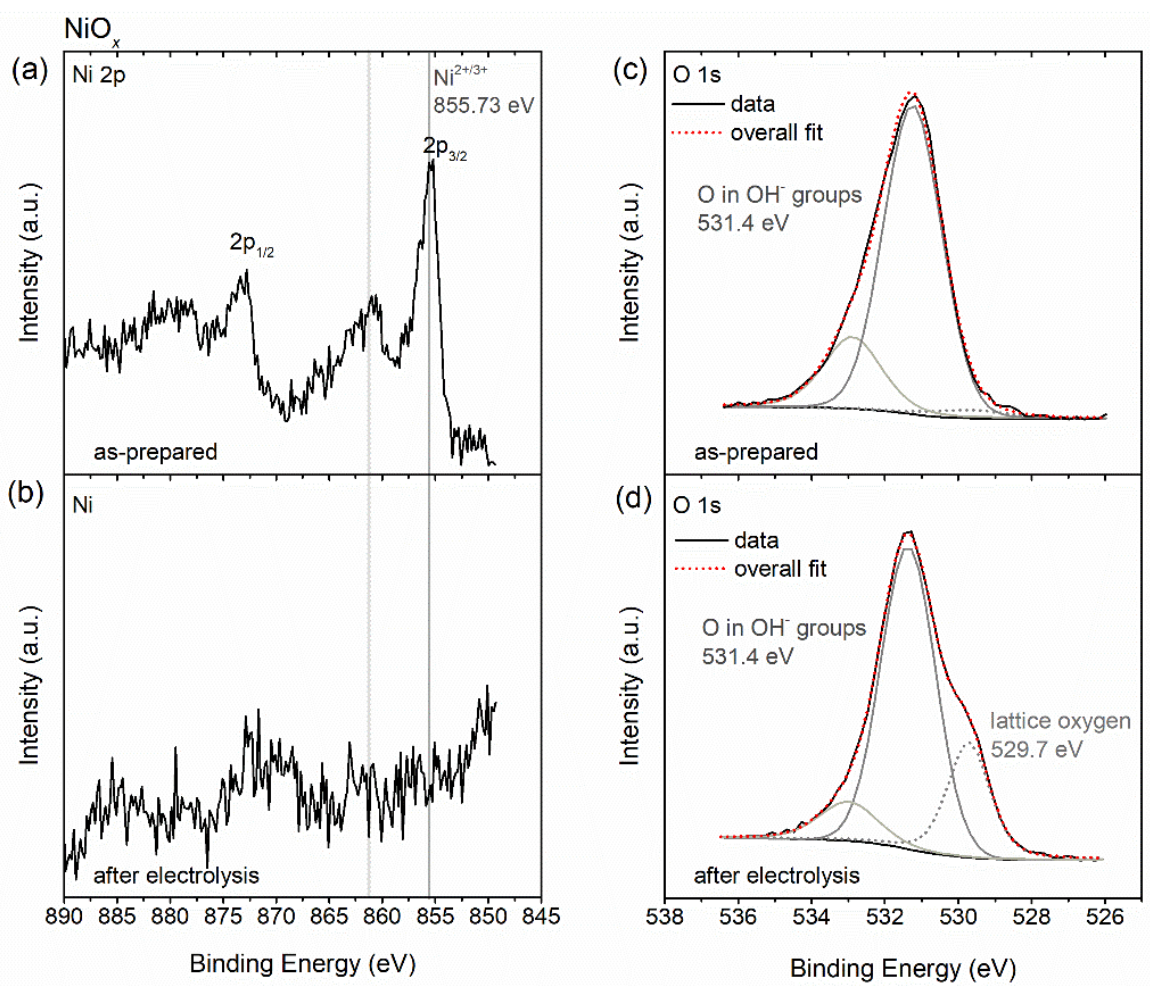

Figure S5. Ni $2 p$ and O 1s X-ray photoelectron spectra of $(a, c)$ as-prepared and $(b, d)$ after-electrolysis $\mathrm{NiO}_{x}$ samples. The as-prepared samples were subjected to galvanostatic electrolysis at a current density of $5 \mathrm{~mA} / \mathrm{cm}^{2}$ in $1 \mathrm{M} \mathrm{KOH}$ for 6 hours. 

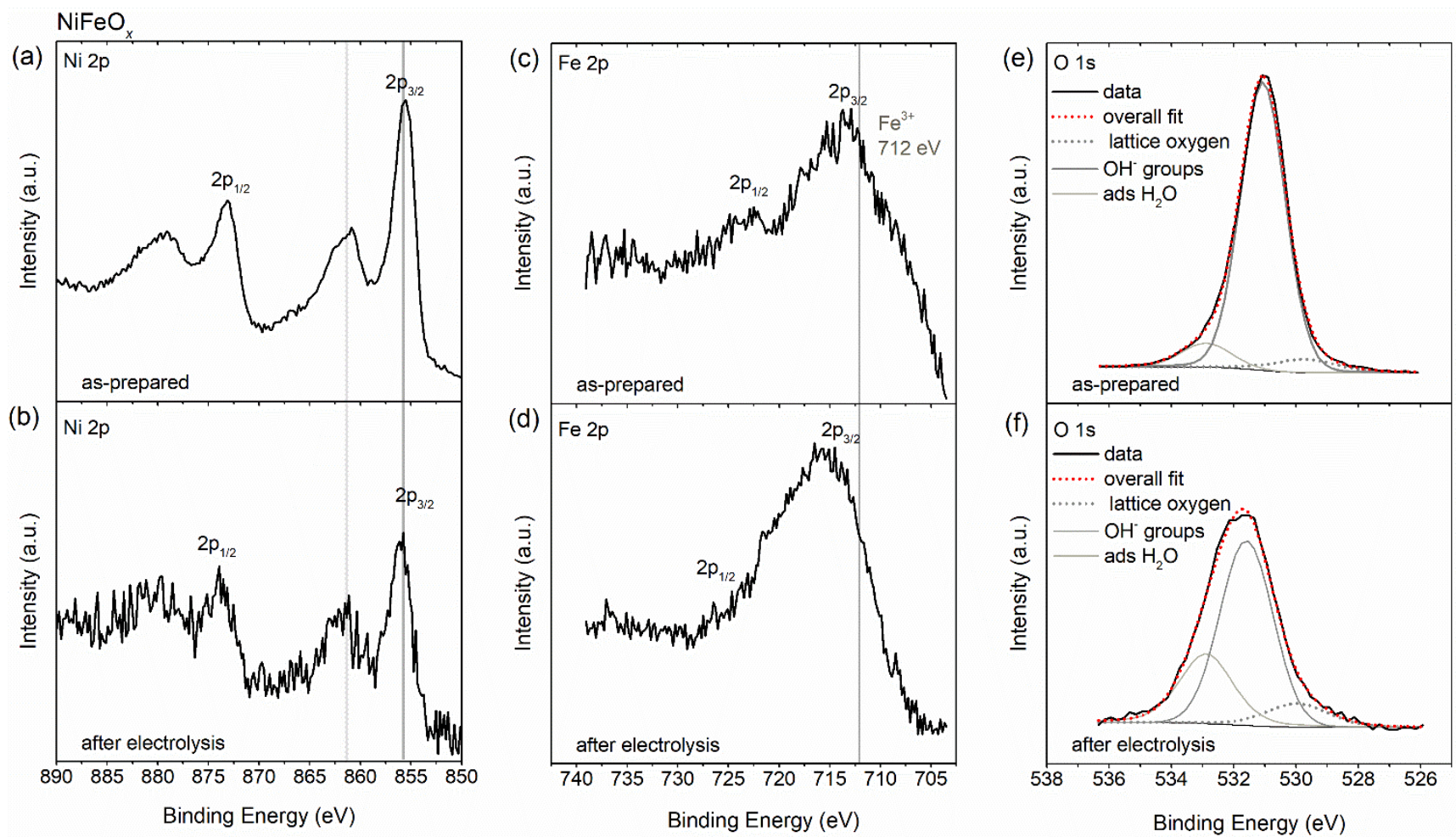

Figure S6. Ni 2p, Fe 2p and O 1s X-ray photoelectron spectra of (a, c, e) as-prepared and (b, d, f) after-electrolysis $\mathrm{NiFeO}_{x}$ samples. The as-prepared samples were subjected to galvanostatic electrolysis at a current density of $5 \mathrm{~mA} / \mathrm{cm}^{2}$ in $1 \mathrm{M} \mathrm{KOH}$ for 6 hours. 


\section{Scanning Electron Microscopy}

- $\mathrm{CoO}_{\mathrm{x}}$

As-prepared:
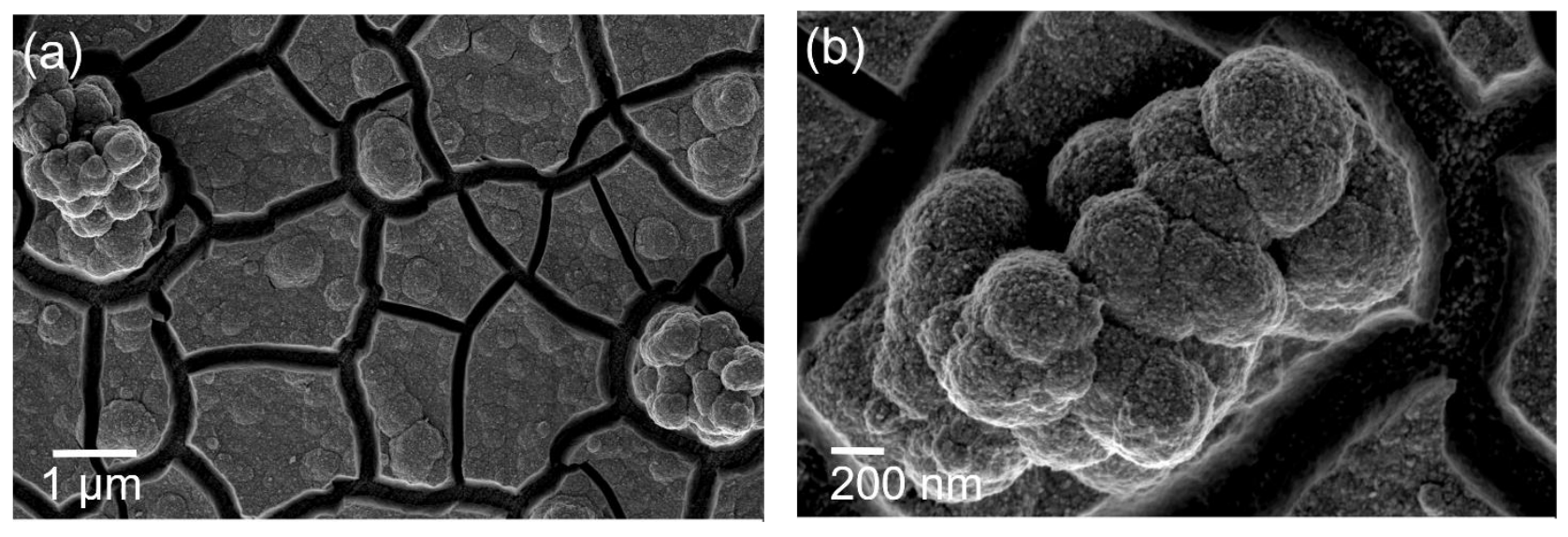

\section{After 6h electrolysis:}
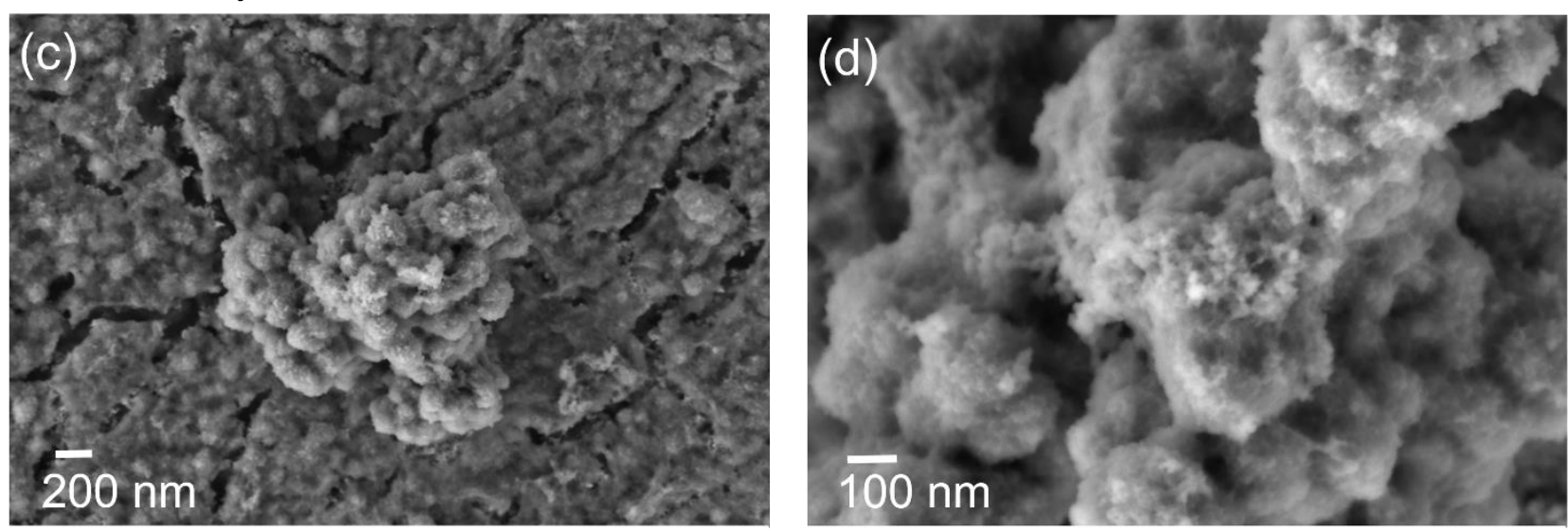

Figure S7: SEM images of $(a, b)$ as-prepared and $(c, d)$ after electrolysis $\mathrm{CoO}_{x}$ samples. The as-prepared samples were subjected to galvanostatic electrolysis at a current density of $5 \mathrm{~mA} / \mathrm{cm}^{2}$ in $1 \mathrm{M} \mathrm{KOH}$ for 6 hours. 
- $\mathrm{CoFeO}_{\mathrm{x}}$

\section{As-prepared:}
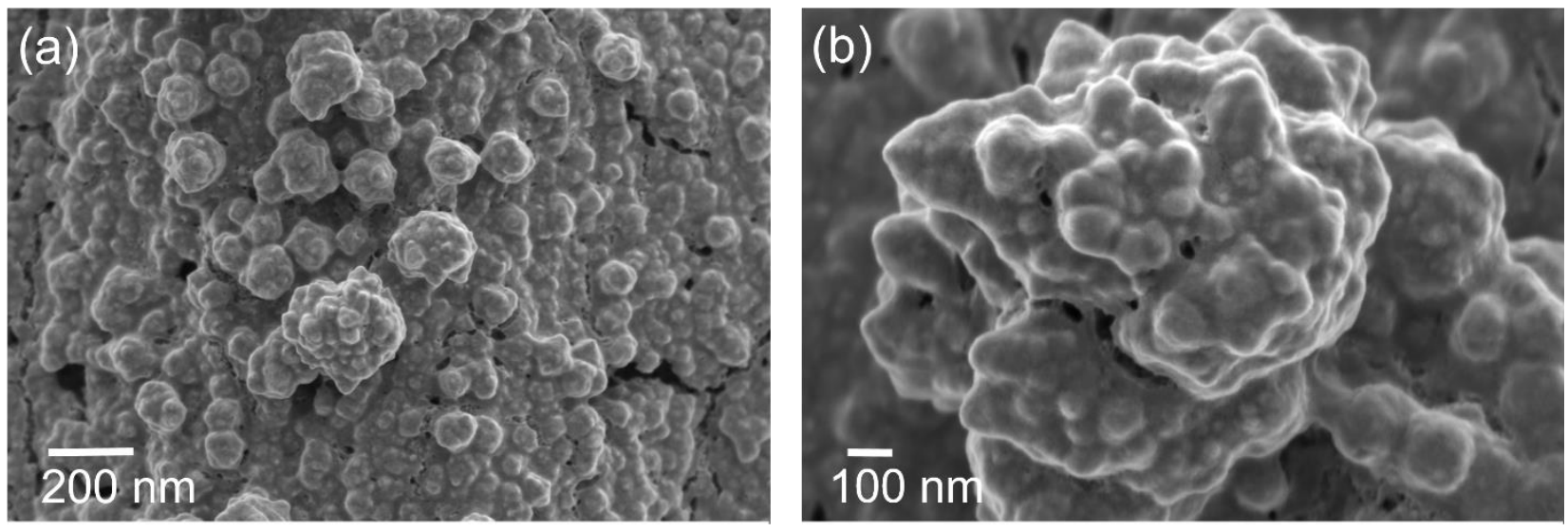

\section{After $6 \mathrm{~h}$ electrolysis:}
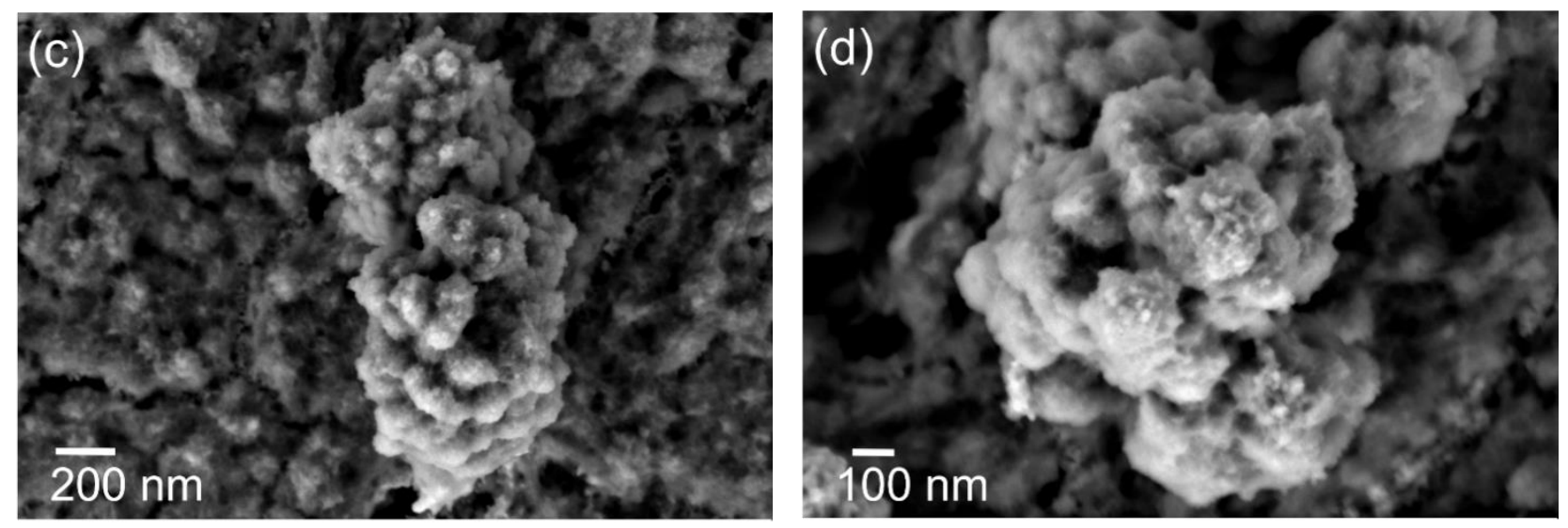

Figure S8. SEM images of $(a, b)$ as-prepared and $(c, d)$ after electrolysis $\mathrm{CoFeO}_{x}$ samples. The as-prepared samples were subjected to galvanostatic electrolysis at a current density of $5 \mathrm{~mA} / \mathrm{cm}^{2}$ in $1 \mathrm{M} \mathrm{KOH}$ for 6 hours. 
- CoFeNiO

As-prepared:
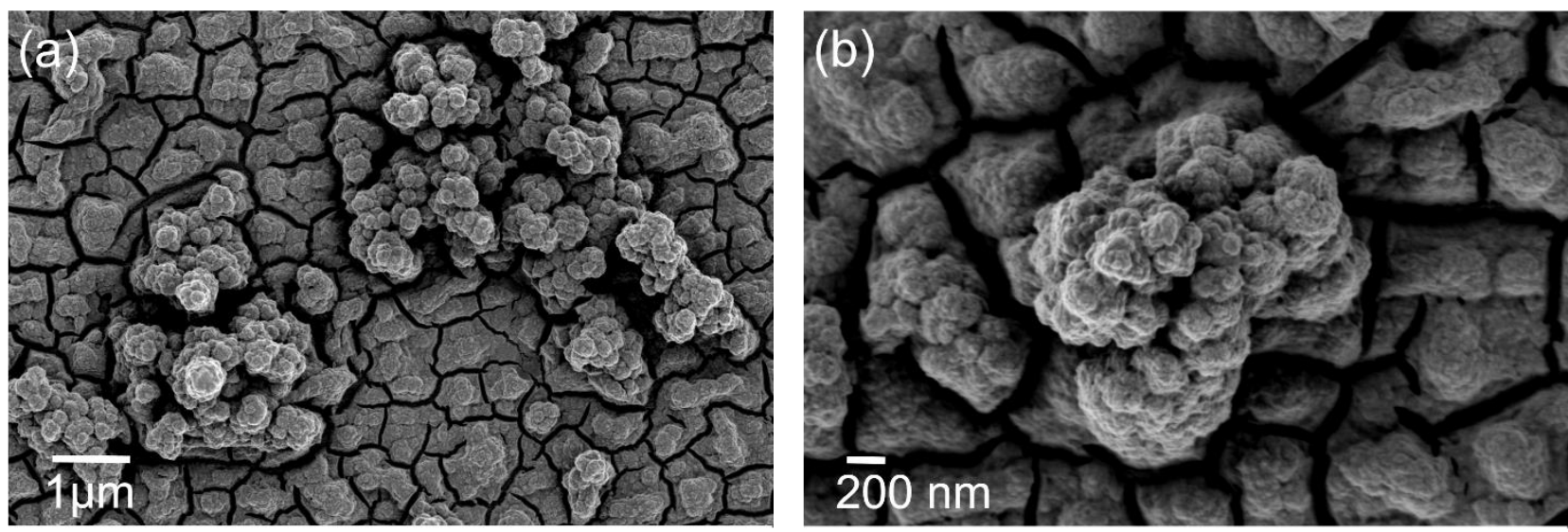

After 6h electrolysis:
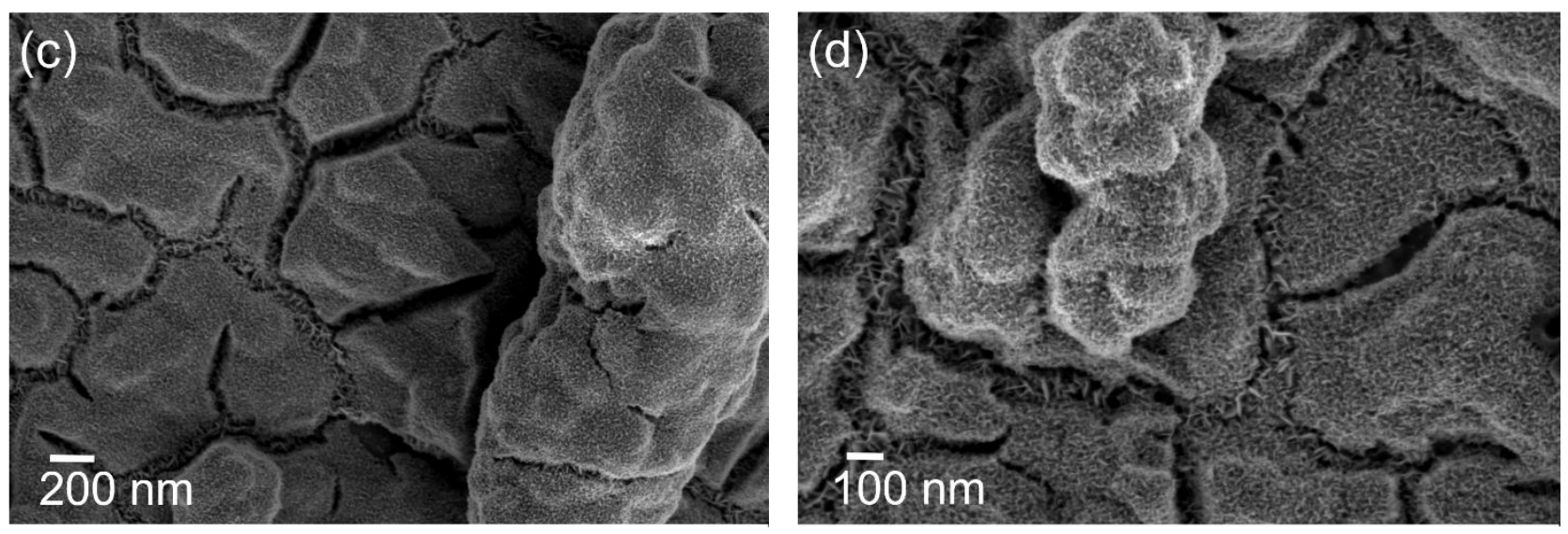

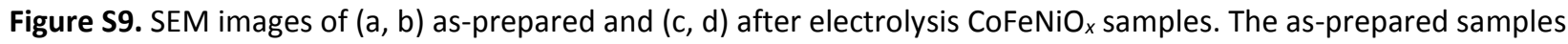
were subjected to galvanostatic electrolysis at a current density of $5 \mathrm{~mA} / \mathrm{cm}^{2}$ in $1 \mathrm{M} \mathrm{KOH}$ for 6 hours. 
- $\mathrm{NiO}_{\mathrm{x}}$

\section{As-prepared:}
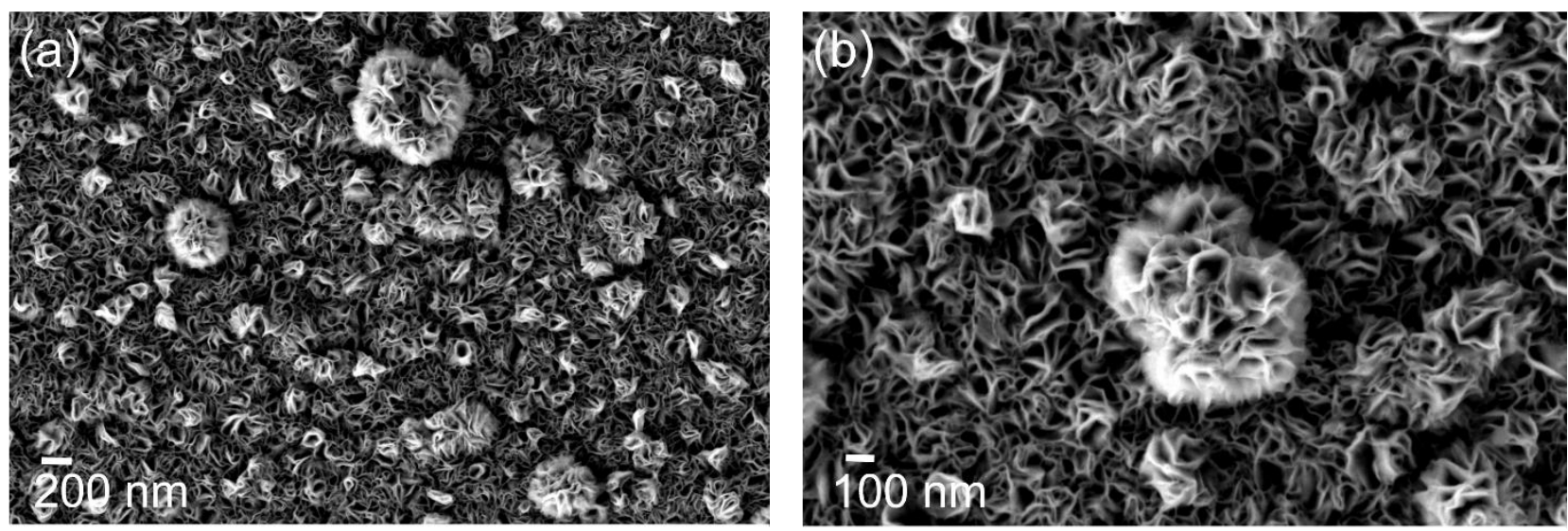

\section{After $6 \mathrm{~h}$ electrolysis:}
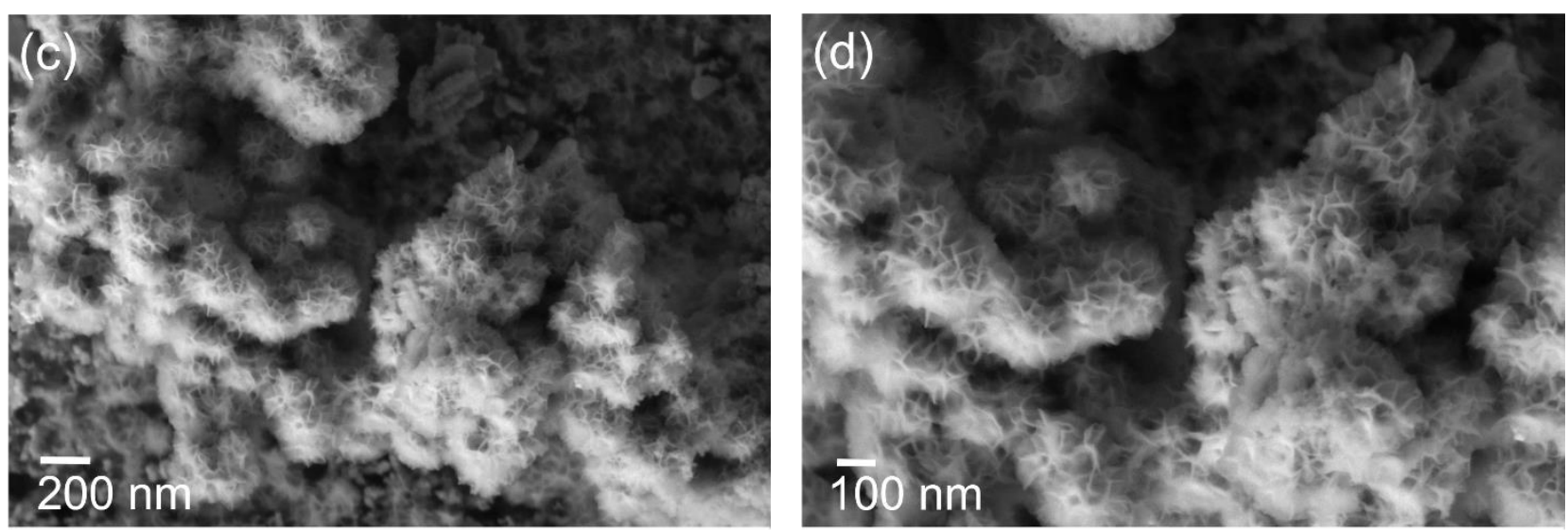

Figure S10. SEM images of (a, b) as-prepared and (c, d) after electrolysis $\mathrm{NiO}_{x}$ samples. The as-prepared samples were subjected to galvanostatic electrolysis at a current density of $5 \mathrm{~mA} / \mathrm{cm}^{2}$ in $1 \mathrm{M} \mathrm{KOH}$ for 6 hours. 
- $\mathrm{NiFeO}_{\mathrm{x}}$

\section{As-prepared:}
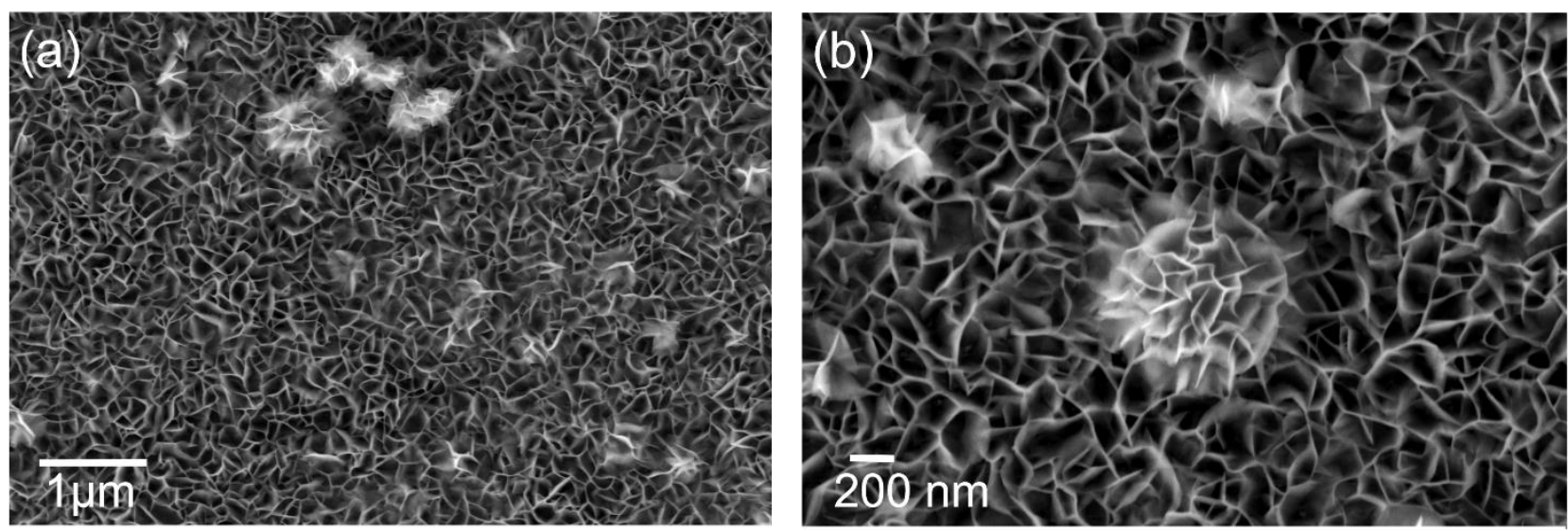

\section{After $6 \mathrm{~h}$ electrolysis:}
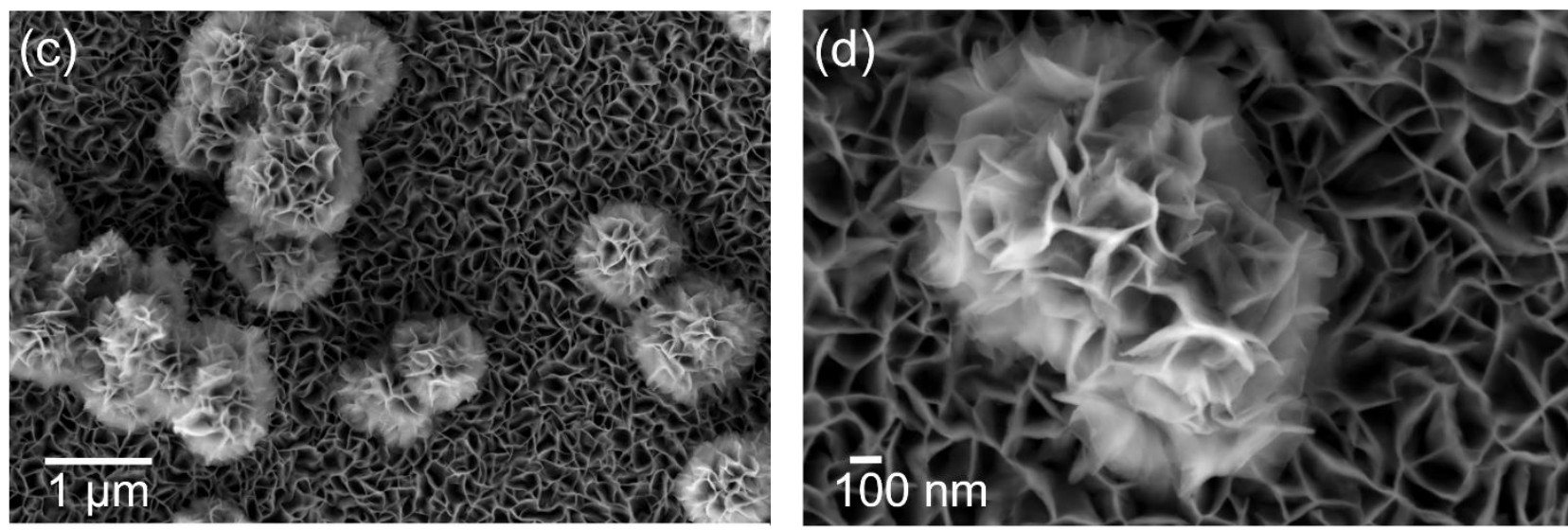

Figure S11. SEM images of (a, b) as-prepared and (c, d) after electrolysis $\mathrm{NiFeO}_{x}$ samples. The as-prepared samples were subjected to galvanostatic electrolysis at a current density of $5 \mathrm{~mA} / \mathrm{cm}^{2}$ in $1 \mathrm{M} \mathrm{KOH}$ for 6 hours. 
(a)

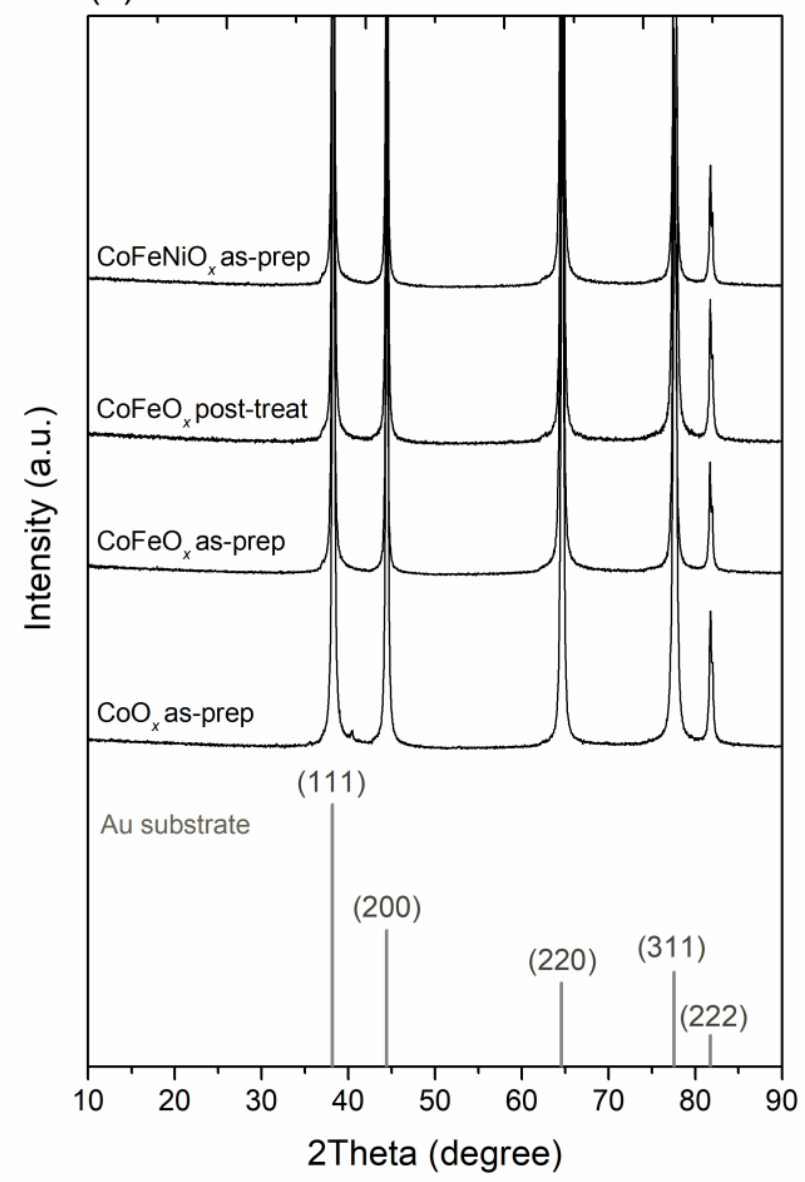

(b)

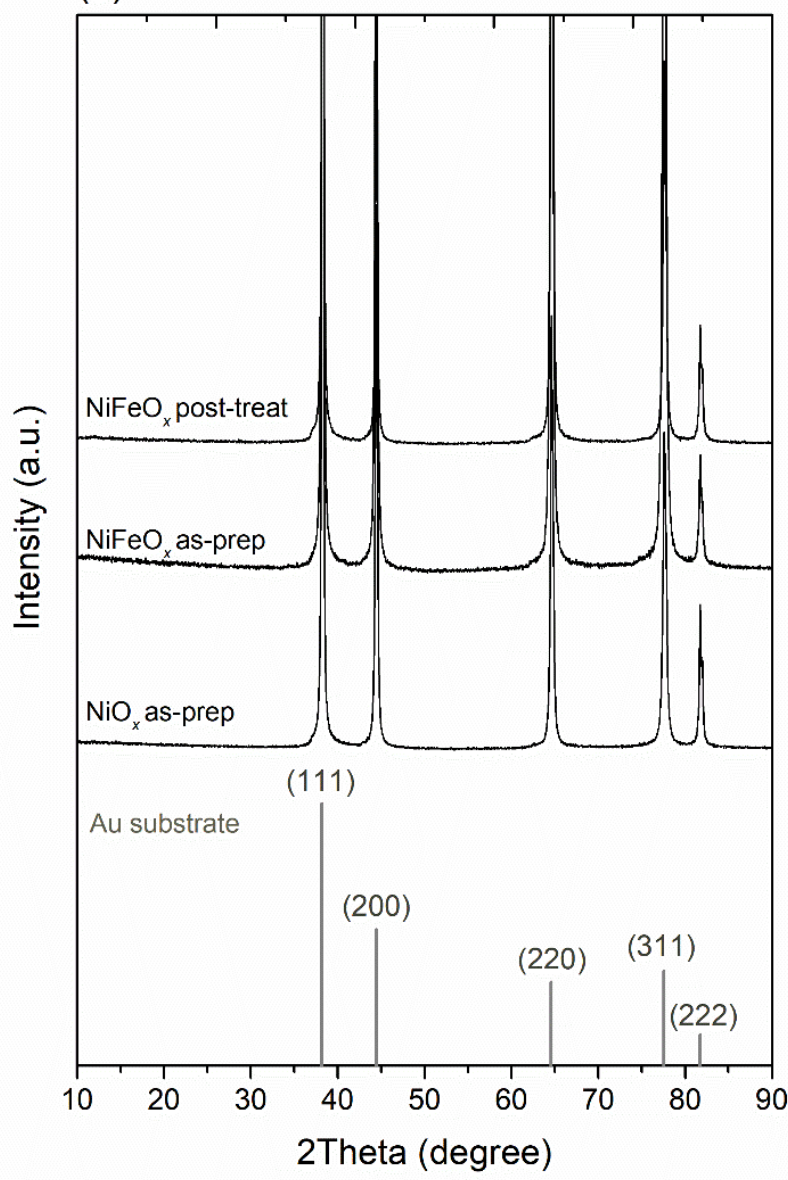

Figure S12. XRD analysis of electrocatalysts; (a) as-prepared $\mathrm{CoO}_{x}, \mathrm{CoFeO}_{x}$ and $\mathrm{CoFeNiO}_{x}$, and (b) as-prepared $\mathrm{NiO}_{x}$ and $\mathrm{NiFeO}_{x}$. CoFeOx and NiFeOx were also analysed after electrolysis as shown in (a) and (b) respectively. The Au substrate is characterised by four distinct peaks corresponding to the Bragg reflections (111), (220), (220) and (311) of the facecentered cubic system. 


\section{Galvanostatic electrolysis in Fe-free electrolytes}

(a)

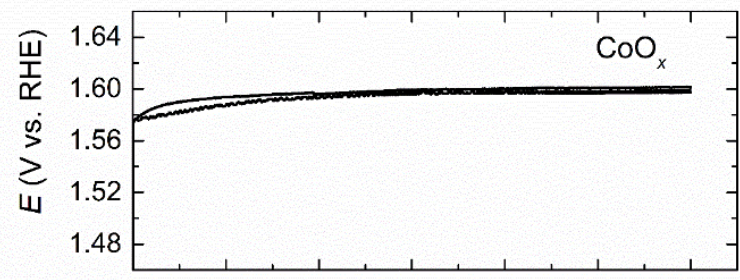

(b)

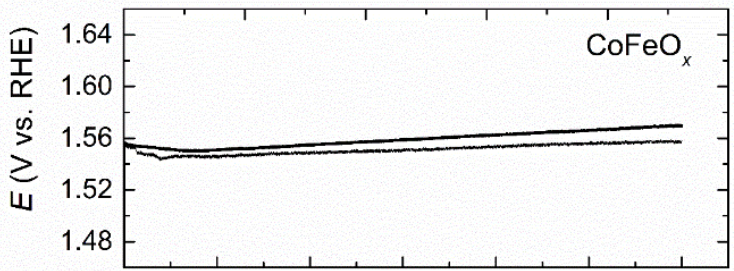

(c)

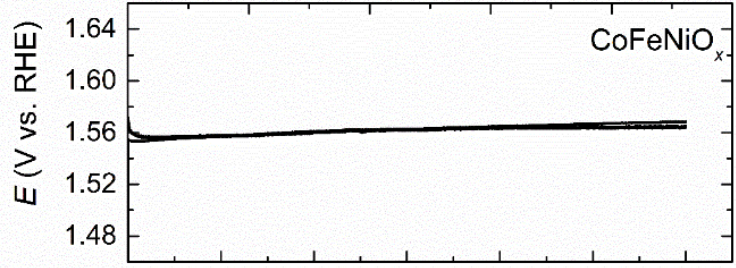

(d)

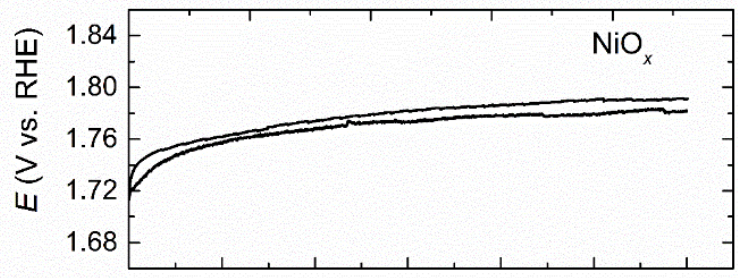

(e)

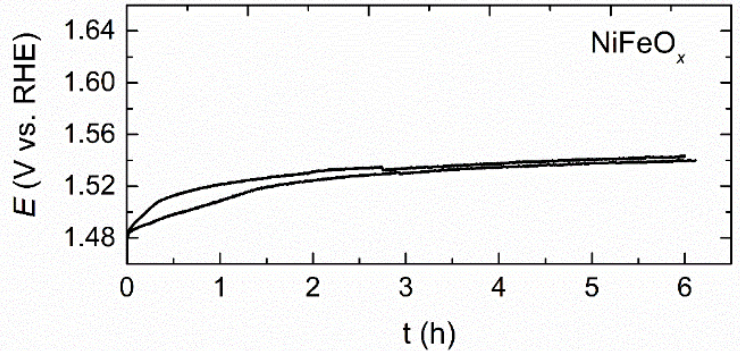

Figure S13. Evolution of potential of the five catalysts during electrolysis at a constant current density of $5 \mathrm{~mA} / \mathrm{cm}^{2}$ in 1 $\mathrm{M}$ Fe-free $\mathrm{KOH}$. Two samples were measured for each catalyst. For Co-containing catalysts, Fe-free $\mathrm{KOH}$ was obtained by treating the electrolyte solutions with Co salts; for Ni-containing catalysts, Fe-free $\mathrm{KOH}$ was obtained by treating the electrolyte solutions with $\mathrm{Ni}$ salts. 


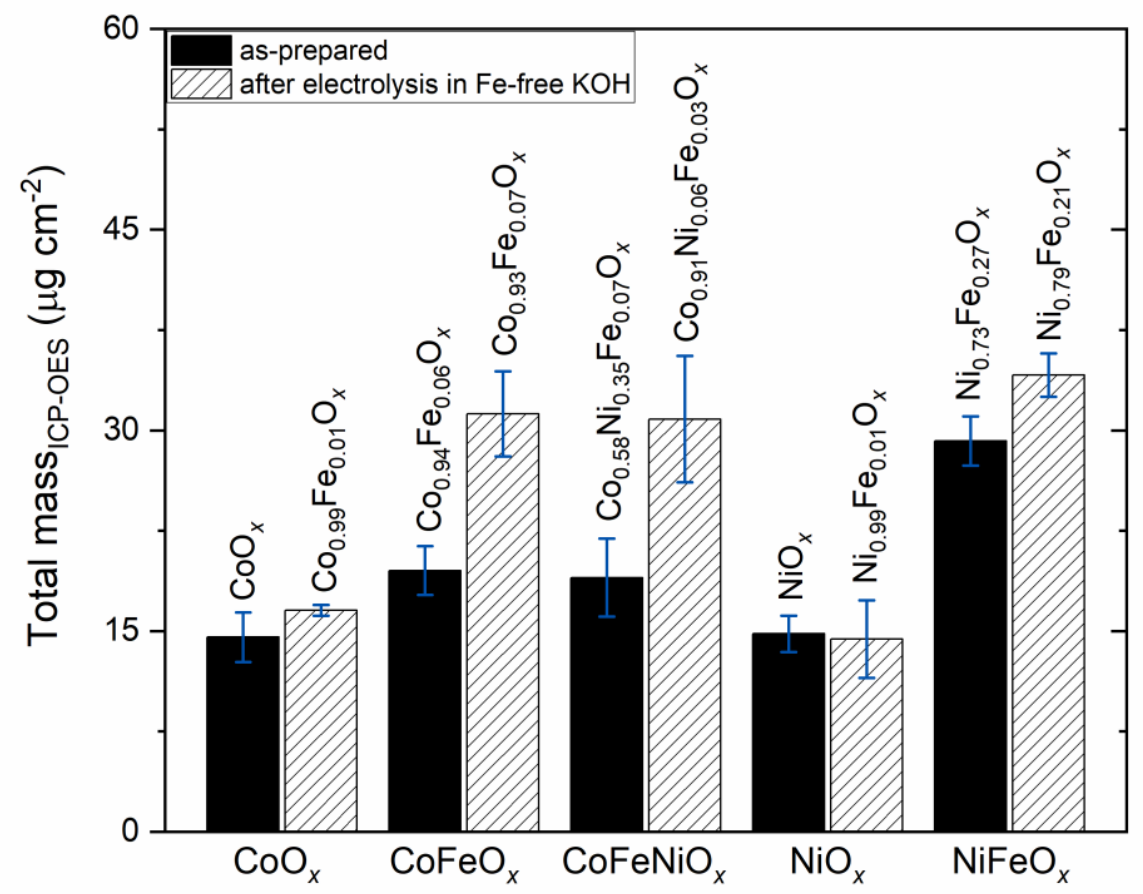

Figure S14. Comparison of the mass of the catalysts before and after electrolysis at a constant current density of 5 $\mathrm{mA} / \mathrm{cm}^{2}$ for $6 \mathrm{~h}$ in $1 \mathrm{M}$ Fe-free $\mathrm{KOH}$. The composition of the mixed oxides catalysts before and after catalysis is indicated. For Co-containing catalysts, Fe-free $\mathrm{KOH}$ was obtained by treating the electrolyte solutions with Co salts; for $\mathrm{Ni}$-containing catalysts, Fe-free $\mathrm{KOH}$ was obtained by treating the electrolyte solutions with $\mathrm{Ni}$ salts. 


\section{Electrochemical Impedance Spectroscopy}

Two electrical circuits were used for fitting the impedance data depending on the EIS response: (a) Randles circuit, and (b) Voigt circuit:

(a)

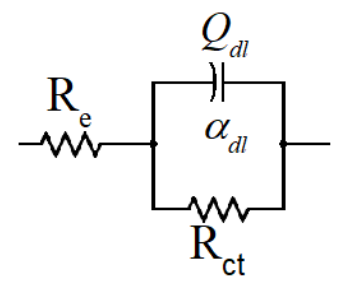

(b)

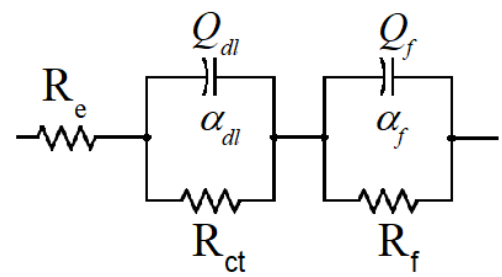

Figure S15. (a) Randles and (b) Voigt circuit.

The Randles circuit (Figure S2a) ${ }^{4}$ comprises a resistor $\left(R_{e}\right)$ for the electrolyte resistance, a resistor $\left(R_{c t}\right)$ related to the charge transfer resistance of the Faradaic process and a constant phase element, $\mathrm{CPE}$, which simulates the double layer capacitance. In this case, the Nyquist plot exhibits one semicircle related to the charge transfer process at the electrolyte/catalyst interface.

The non-ideal capacitive behavior of the electrochemical double-layer is modeled by a constant phase element (CPE), instead of an ideal parallel capacitor. ${ }^{5}$ The CPE has two degrees of freedom; (i) the coefficient, $Q$, and (ii) the constant phase exponent, $\alpha$. The coefficient $Q$ is associated with the electrode capacitance and the exponent $\alpha$ with the deviation from an ideal capacitive response. For $\alpha=1$, the EIS response is that of an ideal parallel capacitor. For $0<\alpha<1$, the behavior of the double layer capacitance deviates from ideality which could be due to a high surface roughness and a more significant frequency dispersion resulting in a depressed semicircle..$^{6,7}$

The simplified Voigt circuit (Figure S2b) includes a second characteristic time constant. The electron transfer resistance, $R_{f}$, can be ascribed to both the resistivity and/or porosity of the film as well as to the contact between the electrode and the catalytic film. The capacitance of the electrode/catalyst interface is simulated again by a CPE with its components $Q_{f}$ and $\alpha_{f}$. The EIS response of low loadings fims $\left(<5 \mathrm{mg} \mathrm{cm}^{-2}\right)$ exhibited one semicircle and Randles circuit was used for the fitting of the data. The EIS response of films with a loading $>5 \mathrm{mg} \mathrm{cm}^{-2}$ presented two semicircles and Voigt circuit was chosen for the fitting of the data. For the calculation of the double layer capacitance, we used a formula proposed by Brug et al..$^{5}$ :

$$
C_{d l}=\left[Q *\left(\frac{1}{R_{e}}+\frac{1}{R_{c t}}\right)^{(a-1)}\right]^{\frac{1}{a}}
$$

Where $C_{d l}$ is the interfacial capacitance 
$Q$ the CPE coefficient,

$\alpha$ the constant phase component $(0<\alpha<1)$,

$R_{e}$ the electrolyte resistance,

$R_{c t}$ the charge transfer resistance. 

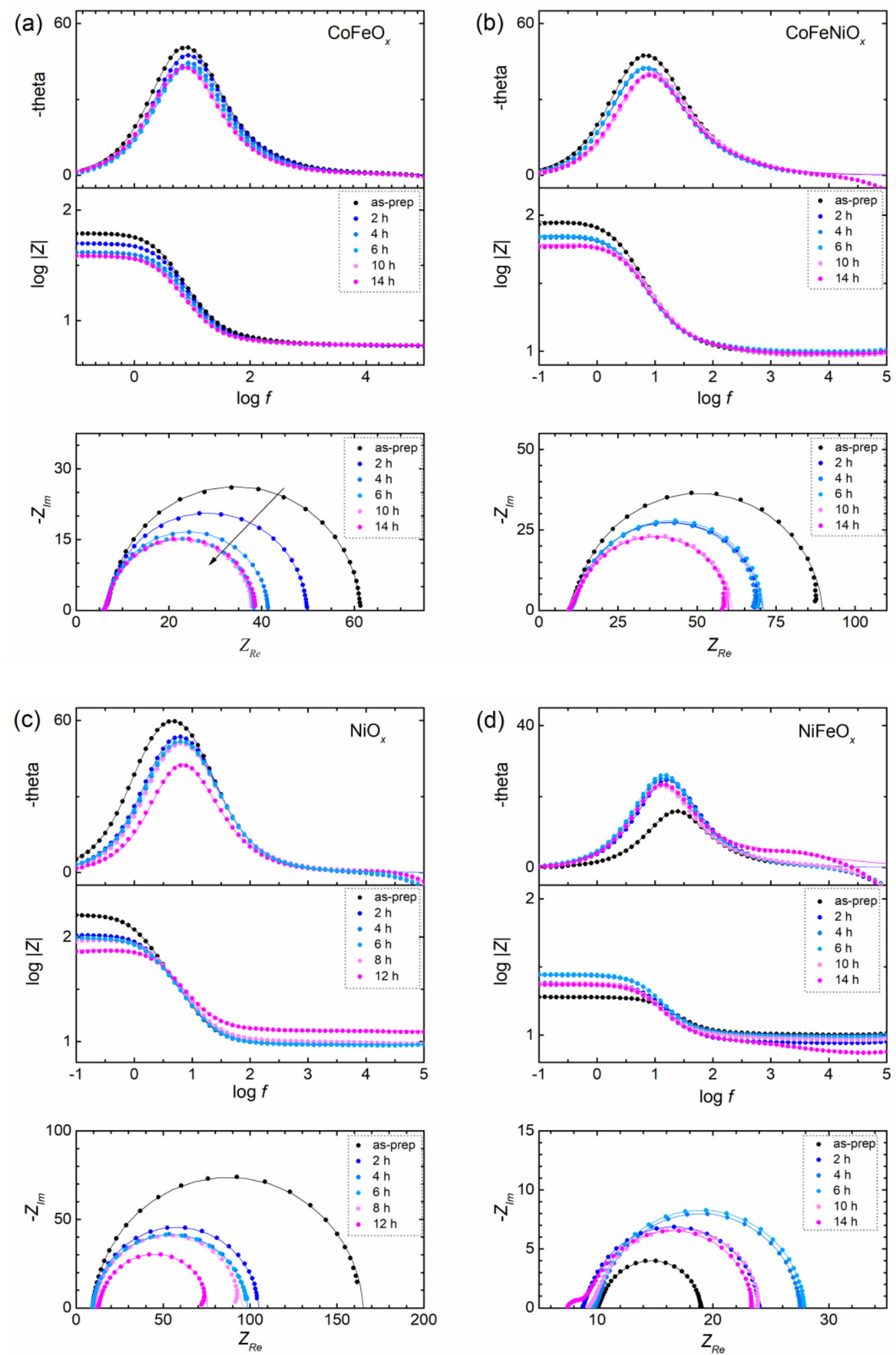

Figure S16. Nyquist and Bode plots for the (a) $\mathrm{CoFeO}_{x}$, (b) $\mathrm{CoFeNiO}_{x}$, (c) $\mathrm{NiO}_{x}$, and (d) $\mathrm{NiFeO}_{x}$. The EIS response of the electrocatalysts was recorded every hour during a 14 hours constant current electrolysis $\left(5 \mathrm{~mA} \mathrm{~cm}^{-2}\right)$. 
(a)

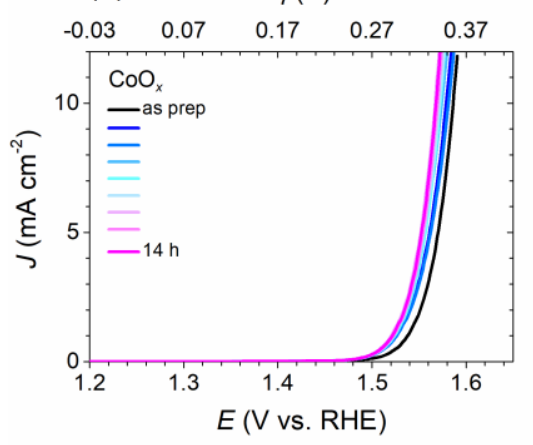

(b)

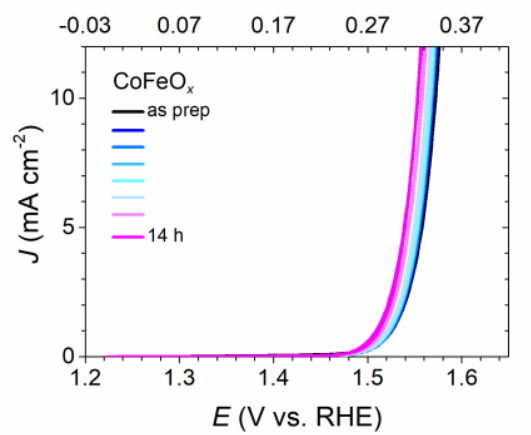

(c)

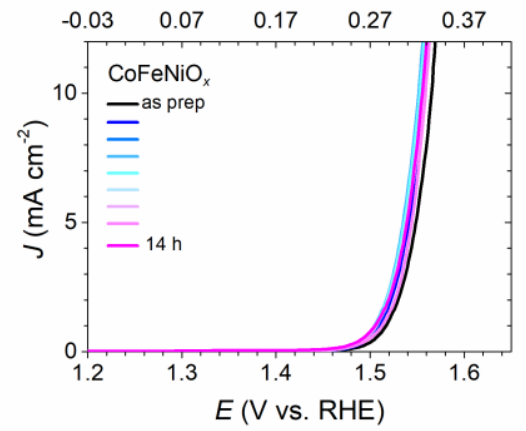

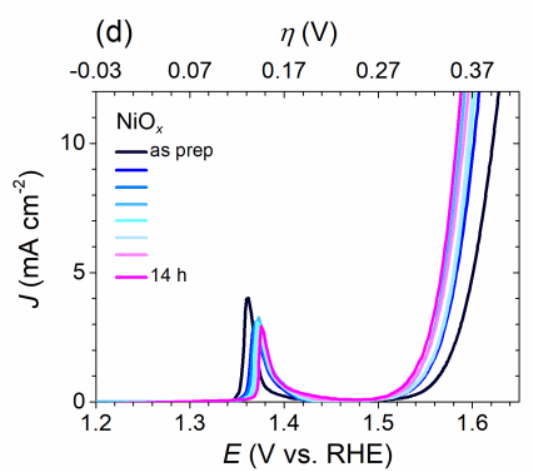

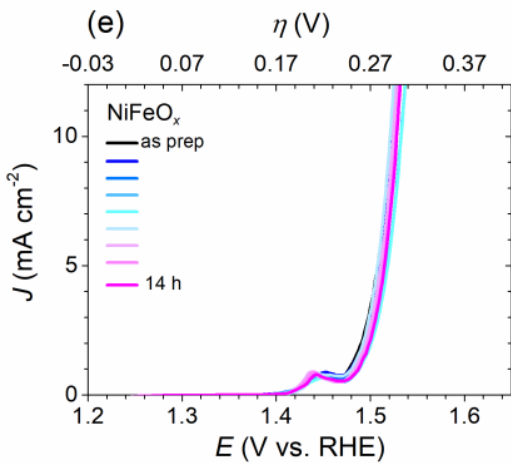

Figure S17. Polarisation curves for all the five catalysts recorded every hour during a 14 h galvanostatic electrolysis at 5 $\mathrm{mA} \mathrm{cm}{ }^{-2}$. Scan rate: $5 \mathrm{mV} / \mathrm{s}$. 
Table S1. Activity metrics for as-prepared and after $6 \mathrm{~h}$ constant current electrolysis $\left(5 \mathrm{~mA} / \mathrm{cm}^{2}\right)$ samples.

\begin{tabular}{|c|c|c|c|c|c|c|c|c|}
\hline & & $\begin{array}{l}J_{g,}, 0.35 \mathrm{~V} \\
\left.(\mathrm{~mA} \mathrm{~cm})^{-2}\right)\end{array}$ & $\begin{array}{l}\text { Mass activity } \\
\text { at } \eta=0.35 \mathrm{~V} \\
\qquad\left(\mathrm{~A} \mathrm{~g}^{-1}\right)^{c}\end{array}$ & $\begin{array}{c}\text { TOF }_{0.35 \mathrm{v}} \\
\left(\mathrm{s}^{-1}\right)\end{array}$ & $\begin{array}{l}\eta_{10 \mathrm{~mA}} \\
\mathrm{~cm}^{-2} \\
(\mathrm{mV})\end{array}$ & $\begin{array}{l}\text { Tafel slope } \\
\left(\mathrm{mVdec}^{-1}\right)\end{array}$ & $\begin{array}{c}J_{s, 0.35 \mathrm{~V}} \\
\left(\mathrm{~mA} \mathrm{~cm}{ }^{-2}\right. \\
\mathrm{ECSA})^{b}\end{array}$ & $\begin{array}{c}\text { Roughness } \\
\qquad\left(\mathrm{R}_{\mathrm{s}}\right)^{e}\end{array}$ \\
\hline \multirow[t]{2}{*}{$\mathrm{CoO}_{x}$} & as-prep & 7.70 & 570 & 0.17 & 357 & 45 & 0.026 & 290 \\
\hline & after $6 \mathrm{~h}$ & 15.70 & 1600 & 0.47 & 340 & 39 & 0.054 & 293 \\
\hline \multirow{2}{*}{$\mathrm{CoFeO}_{x}$} & as-prep & 16.50 & 1523 & 0.36 & 340 & 41 & 0.15 & 105 \\
\hline & after $6 \mathrm{~h}$ & 22.50 & 3211 & 0.76 & 330 & 39 & 0.14 & 156 \\
\hline \multirow[t]{2}{*}{$\mathrm{CoFeNiO}_{x}$} & as-prep & 17.20 & 1975 & 0.45 & 323 & 39 & 0.17 & 108 \\
\hline & after $6 \mathrm{~h}$ & 21.50 & 2340 & 0.55 & 330 & 42 & 0.18 & 121 \\
\hline \multirow[t]{2}{*}{$\mathrm{NiO}_{x}$} & as-prep & 2.30 & 152 & 0.04 & 395 & 58 & 0.017 & 136 \\
\hline & after $6 \mathrm{~h}$ & 5.00 & 291 & 0.07 & 360 & 43 & 0.036 & 126 \\
\hline \multirow[t]{2}{*}{$\mathrm{NiFeO}_{x}$} & as-prep & $15.40^{a}$ & $1017^{a}$ & $0.24^{a}$ & 290 & 39 & $0.14^{a}$ & 113 \\
\hline & after $6 \mathrm{~h}$ & $14.40^{a}$ & $1113^{a}$ & $0.25^{a}$ & 298 & 38 & $0.15^{a}$ & 103 \\
\hline \multicolumn{9}{|c|}{${ }^{a}$ For the $\mathrm{NiFeO}_{x}$ these values are reported at $\eta=0.30 \mathrm{~V} .{ }^{b}$ The ECSA values were determined by EIS analyses. } \\
\hline \multicolumn{9}{|c|}{${ }^{c}$ The mass activity was calculated based on the loading of the catalysts as determined by ICP. } \\
\hline \multicolumn{9}{|c|}{${ }^{d}$ The working electrode was an Au-coated quartz crystal $\left(d=0.205 \mathrm{~cm}^{2}\right)$} \\
\hline \multicolumn{9}{|c|}{ e The roughness is calculated by dividing the ECSA by the geometric surface area of the working electrode ( $d=$} \\
\hline $0.205 \mathrm{~cm}^{2}$ & & & & & & & & \\
\hline
\end{tabular}




\section{REFERENCES}

1. S. Bruckenstein and M. Shay, Electrochimica Acta, 1985, 30, 1295-1300.

2. D. A. Buttry and M. D. Ward, Chem. Rev., 1992, 92, 1355-1379.

3. A. R. Hillman, J. Solid State Electrochem., 2011, 15, 1647-1660.

4. J. E. B. Randles, Discuss. Faraday Soc., 1947, 1, 11.

5. G. J. Brug, A. L. G. van den Eeden, M. Sluyters-Rehbach and J. H. Sluyters, J. Electroanal. Chem. Interfacial Electrochem., 1984, 176, 275-295.

6. R. L. Doyle, I. J. Godwin, M. P. Brandon and M. E. G. Lyons, Phys. Chem. Chem. Phys., 2013, 15, 1373713783.

7. R. L. Doyle and M. E. G. Lyons, Phys. Chem. Chem. Phys., 2013, 15, 5224-5237. 